\title{
Structural and Catalytic Properties of Sulphated Zirconia doped by Zn Oxide
}

\author{
Sh. M. El-Dafrawy*, Mervat Farag, Sohier Abd El Hakam \\ and Sh. M. Hassan \\ Chemistry Department, Faculty of Science, Mansoura \\ University, Egypt.
}

\begin{abstract}
QULFATED zirconia (SZ) and zinc supported sulfated $\checkmark$ zirconia $(\mathrm{Zn} / \mathrm{SZ})$ catalysts were synthesized, characterized and evaluated by coumarin synthesis reaction. The reaction was carried by reacting resorcinol and ethyl acetoacetate with a molar ratio 1:2 respectively. The investigated $\mathrm{SZ}$ and $\mathrm{Zn} / \mathrm{SZ}$ catalysts were prepared by the simple impregnation method with an aqueous solution of $\mathrm{H}_{2} \mathrm{SO}_{4}$ as a precipitating agent, followed by drying in rotary and finally calcined at $600{ }^{\circ} \mathrm{C}$ for 3 hrs. The physicochemical properties of the investigated catalysts were characterized by the X-ray diffraction (XRD), scanning electron microscope (SEM), transmission electron microscope (TEM) and potentiometric titration to characterize the number and the strength of the acid sites. The $6 \% \mathrm{Zn} / \mathrm{SZ}$ catalyst possessed the maximum catalytic activity as well the number of acid sites. Increase of the tetragonal phase content in $\mathrm{ZrO}_{2}$ increases the catalytic activity.
\end{abstract}

Keywords:Sulfated zirconia, impregnation method, Coumarine synthesis reaction and potentiometric titration.

In recent years, green and an environmental chemistry have attracted much attention around the world; great and continuous efforts are focused on the design and implementation of chemical technologies processes that achieve these goals. Heterogeneous catalysts and especially solid acid catalysts exhibit a significant role as a contributor in this field.

Zirconia has been prevalently studied due to its employment as a support; however, strong active sites can be produced by modification of zirconia by $\mathrm{H}_{2} \mathrm{SO}_{4}$ treatment. The successive developments of this catalyst play a remarkable role in the synthesis of chemicals like coumarins, organic esters, N, N diphenylenediamines, etc. [1]. Zirconia exists in several crystalline forms such as monoclinic, tetragonal and cubic [2-4]. SZ has high thermal stability, easy preparation, less cost, high boiling point, and good corrosion resistant in acidic and alkaline environment. In addition a very high activity, selectivity and stability which making it an efficient catalyst for a number of industrially

*Corresponding author e-mail: shomirage@ yahoo.com

DOI: 10.21608/ejchem.2017.3288

(C) 2017 The National Information \& Documentation Center (NIDOC) 
important reactions such as hydrocarbon isomerization, cyclization [5-7], methanol synthesis [8], esterification [9], transesterification [10], reduction of $\mathrm{NO}_{\mathrm{x}}[11,12]$, condensation [13-15] and acetylation [16].

Special attention has been given to the preparation, characterization, and catalytic investigation of SZ which possesses more acid sites than other sulfated metal oxides, so SZ is considered super acidic according to acidity measurements, alkane transformation and isobutene conversion [17].

Based on the Hammett indicator test, SZ is reported to exhibit super acidity with $\mathrm{H}_{\mathrm{o}}<-16$ [17-19]. The catalytic and structural properties of the SZ depend on a number of factors including preparation methods, precursor used, precursor concentration, $\mathrm{pH}$, sulfonating agent and calcination temperature [20]. The effect of preparation conditions and calcination temperature on the structural phases, textural characteristics, number and types of active acidic sites on the surface of the sulfated zirconia were investigated using X-ray diffraction (XRD), scanning electron microscope (SEM) and transmission electron microscope (TEM). It is observed that the catalytic activity of unmodified SZ is often not strong enough and for this reason a number of transition metals like (Fe, Mn, Co, Al, Zn, Ni, $\mathrm{Cr}$, .....etc.) have added to SZ resulting in catalysts with higher activity than unmodified SZ [4, 21]. So in this work, the differences of catalytic behavior over undoped SZ and $\mathrm{Zn}$ doped SZ have been studied with relation to crystalline phase, acidity and $\mathrm{Zn}$ concentration.

Coumarins are the benzo-2-pyrone derivatives mainly found in plants of the family of Rutaceae and Umbelliferae [13,21,22]. They are used in pharmaceuticals [23,24], insecticides [25], fluorescent [26] and dye lasers [27, $28]$. Besides that coumarin play a significant role in various bioactivities like antimicrobial [29], anticancer [30-32], inhibitory of HIV-1 [33], antioxidant [34] and antiviral [35].

The extraction of coumarin from plants is mortal and takes up very much time, moreover needs sophisticated technology [13, 15, 22]. Chemically, coumarins can be synthesized by various methods such as the Pechmann reaction, Knoevenagel condensation, Claisen rearrangement, Perkin, Witting, Reformatsky and catalytic cyclization reactions [36,37]. However, acid catalyzed Pechmann reaction is a simple and commonly used method for synthesizing coumarins from activated phenols, mostly m-substituted phenols containing electron donating substituent at m-position and $\beta$-keto-esters or an unsaturated carboxylic acids $[11,13,38]$

Traditional Pechmann reaction was catalyzed in presence of concentrated $\mathrm{H}_{2} \mathrm{SO}_{4}, \mathrm{HCl}$, and phosphorus pentoxide or trifluoroacetic acid but in these methods a long reaction time and very high reaction temperatures are required. Furthermore, these acids are corrosive, required in excess, difficult to separate and create critical environmental problems due to getting rid of the post reaction wastes $[13-15,21]$. To overcome these defects heterogeneous catalysts exhibit a Egypt. J. Chem. 60, No.2 (2016) 
remarkable role in Pechmann condensation reactions [13-14], especially nanocrystalline sulfated zirconia catalyst, which exhibits excellent performance under solvent free conditions [39].

Our aim in this work is showing to what extent $\mathrm{Zn}$ can improve the catalytic activity of sulfated zirconia, as well find a relation between calcination temperature, acidity and catalytic activity.

\section{Materials}

\section{Experimental}

Zirconium nitrate $\mathrm{Zr}\left(\mathrm{NO}_{3}\right)_{4}$, Zinc nitrate $\mathrm{Zn}\left(\mathrm{NO}_{3}\right)_{2} \cdot 6 \mathrm{H}_{2} \mathrm{O}$, Distilled water, Sulfuric acid $\left(\mathrm{H}_{2} \mathrm{SO}_{4}\right)$, Resorcinol $\left(\mathrm{C}_{6} \mathrm{H}_{6} \mathrm{O}_{2}\right)$, Ethyl aceto acetate $\left(\mathrm{C}_{6} \mathrm{H}_{10} \mathrm{O}_{3}\right)$.

\section{Catalyst preparation}

SZ catalyst was prepared by using the simple impregnation method [11] as follow: $17.5 \mathrm{gm}$ of zirconium nitrate was dissolved in $400 \mathrm{ml}$ distilled water under stirring. Sulfuric acid with $2 \mathrm{~N}$ concentration was added dropwise to zirconium sol with vigorous and continuous stirring at room temperature, and then white gel was formed. Subsequently, solvent was then removed and the resultant white gel was dried in rotary at $90{ }^{\circ} \mathrm{C}$. Finally, the dried powder calcined at different calcination temperatures $400,500,600$, and $800{ }^{\circ} \mathrm{C}$ for $3 \mathrm{hrs}$ with a heating rate of $20^{\circ} \mathrm{C} \cdot \mathrm{min}^{-1}$.

$4,6,8,10$, and $20 \% \mathrm{Zn} / \mathrm{SZ}$ was synthesized by dissolving appropriate amounts of zinc nitrate each in $50 \mathrm{ml}$ distilled water and then added dropwise to the $\mathrm{SZ}$ white gel under continuous stirring. The mixture was stirred magnetically for $2 \mathrm{hrs}$, and then it was dried in rotary at $90{ }^{\circ} \mathrm{C}$. The synthesized samples were calcined at $400,500,600$, and $800{ }^{\circ} \mathrm{C}$ for 3 hrs with a heating rate of $20{ }^{\circ} \mathrm{C} \cdot \mathrm{min}^{-1}$.

\section{Characterization}

$X R D$ analysis

The powder diffraction patterns were recorded on X-ray powder diffractometer (XRD) PW 150 (Philips) using Ni filtered $\mathrm{Cu} \mathrm{K \alpha}$ radiation $(\lambda=1.540 \AA$ ) at 40 $\mathrm{kV}, 30 \mathrm{~mA}$ and a scanning range $2 \Theta$ of $18^{\circ}-80^{\circ}$. The percentage of zirconia tetragonal phase was estimated with the following formula [40].

$\%$ Tetragonal $=\left[\frac{I T(2 \theta=30.15)}{I T(2 \theta=30.15)+\left(\frac{I M(2 \theta=28.16)+I M(2 \theta=31.44)}{2}\right)}\right] \times 100$

The crystallite size $(\mathrm{nm})$ was calculated from the reflection of tetragonal zirconia phase at $2 \mathrm{hrs}$ of 30.15 , using the Scherrer relationship [41,42].

$$
\mathrm{D}=\frac{K \lambda}{\beta \cos \theta}
$$

where $\mathrm{k}$ is the crystallite shape constant $(\approx 1), \lambda$ is the radiation wavelength $(\AA)$, 
$\beta$ is the line breadth (radians) and $\Theta$ is the Bragg angle.

Microscopic studies

Transmission electron microscopy (TEM) images and particle size were obtained using JEOL-JEM-2100 transmission electron microscope operating at $120 \mathrm{KV}$. TEM samples were prepared by dipping suspension of fine sample powders onto a copper grid coated with a holey carbon foil and dried at ambient temperature. While scanning electron microscopy (SEM) in which the catalysts surface images of the nano catalysts samples were obtained using jeol-jsm-6510 LV scanning electron microscope. SEM was used to study the morphology and the chemical composition of samples; the samples were prepared by placing a very small quantity of the catalyst particles on a gold coated grid before SEM analysis [43].

\section{Potentiometric titration}

The total acidity of the solid samples was measured by non-aqueous potentiometric titration [44]. The activated catalyst $(0.1 \mathrm{gm})$ was suspended in 10 $\mathrm{mL}$ acetonitrile. Then, the suspension was titrated with $0.01 \mathrm{~N}$ n-butyl amine into acetonitrile. The electrode potential variation was measured with an Orion 420 digital model using a double junction electrode.

\section{Catalytic reaction}

The Pechmann condensation reaction was carried out under reflux conditions. Mixture of resorcinol and ethyl acetoacetate was refluxed in the presence of freshly calcined catalyst; the time of reflux and the amount of catalyst were varied to optimize the yield of coumarin.

In a typical reaction, the mixture of resorcinol and ethyl acetoacetate were taken in 1:2 molar ratio respectively in around flask and homogenized at $120{ }^{\circ} \mathrm{C}$ [45,46]. Freshly calcined catalyst $(0.1 \mathrm{gm})$ was added and refluxed for $2 \mathrm{hrs}$ and then the content of the flask was poured onto crushed ice followed by scratching until the solid product is formed. These conditions were selected based on previous results $[47,48]$.

The solid product was separated by filtration, dried and the organic compound was extracted with the hot ethanol. The catalyst remains undissolved and was separated by filtration. From alcoholic solution, 7-hydroxy-4-methyl coumarin was recovered by evaporating the solvent on hot water bath.

The product was characterized by melting point and FTIR. The yield of $7-$ hydroxy-4methylcoumarin was obtained as follows [49]:

$$
\text { Yield }(w t \%)=\left(\frac{\text { obtained weight of product }}{\text { theoritical weight of product }}\right) \times 100
$$

Egypt. J. Chem. 60, No.2 (2016) 
$X R D$ analysis

\section{Results}

XRD patterns exhibit the influence of different $\mathrm{Zn}$ concentrations and calcination temperatures on the crystal phase and crystallite size of SZ as shown in Fig. 1 and 2. The peaks at $2 \Theta=28^{\circ}$ and $31^{\circ}$ are characteristic to monoclinic phase, while peak at $2 \Theta=30^{\circ}$ refers to tetragonal phase which is catalytically the more active phase [50]. From Fig. 1, it is observed that undoped SZ shows major monoclinic phase in addition to tetragonal phase. SZ with $6 \% \mathrm{Zn}$ concentration gives more stability to tetragonal phase as result of decreasing in a lattice spacing and a particle size of zirconia [51,52], and hence retard transformation from metastable phase to monoclinic phase, since the smaller particle size the greater surface energy contributing to tetragonal phase stability [53]. Therefore stability of tetragonal phase might be related to introducing of phase stabilizers in the surface (like sulfate group) or in the bulk (like cationic dopant) [11]. Here, tetragonal phase stabilization caused by introducing of $6 \% \mathrm{Zn}$ into SZ. However, increasing $\mathrm{Zn}$ concentration more than $6 \%$, the tetragonal phase decreased while monoclinic phase increased. This behavior may be attributed to the large concentration of $\mathrm{Zn}$ which increases randomness, then oxygen diffusion becomes less favorable and the tetragonal phase becomes less stable [54].

Figure 2 shows $6 \% \mathrm{Zn} / \mathrm{SZ}$ catalyst calcined at 500,600 and $800{ }^{\circ} \mathrm{C}$. As revealed from Fig. 2, the catalyst is mainly amorphous at $500{ }^{\circ} \mathrm{C}$, while the best tetragonal phase is observed at $600{ }^{\circ} \mathrm{C}$. Calcination at $800{ }^{\circ} \mathrm{C}$ shows a sharp decrease in the tetragonal phase accompanied by increases in the particle size.

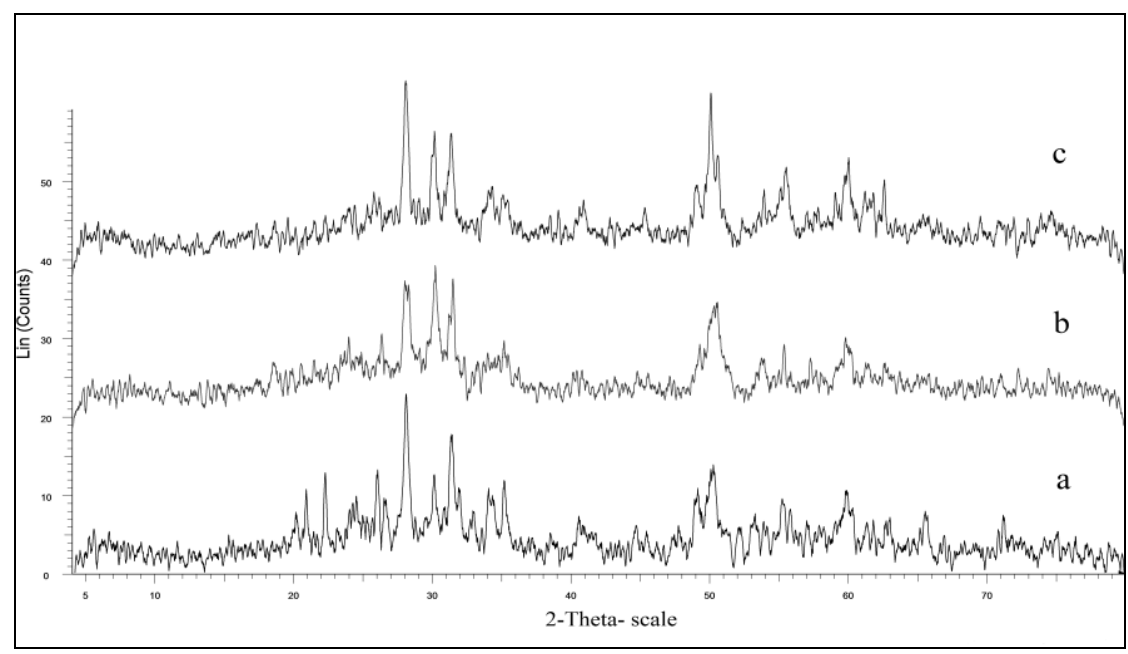

Fig. 1. XRD of (a) $\mathrm{SZ}$, (b) $6 \% \mathrm{Zn} / \mathrm{SZ}$ and (c) $10 \% \mathrm{Zn} / \mathrm{SZ}$ calcined at $600{ }^{\circ} \mathrm{C}$. 


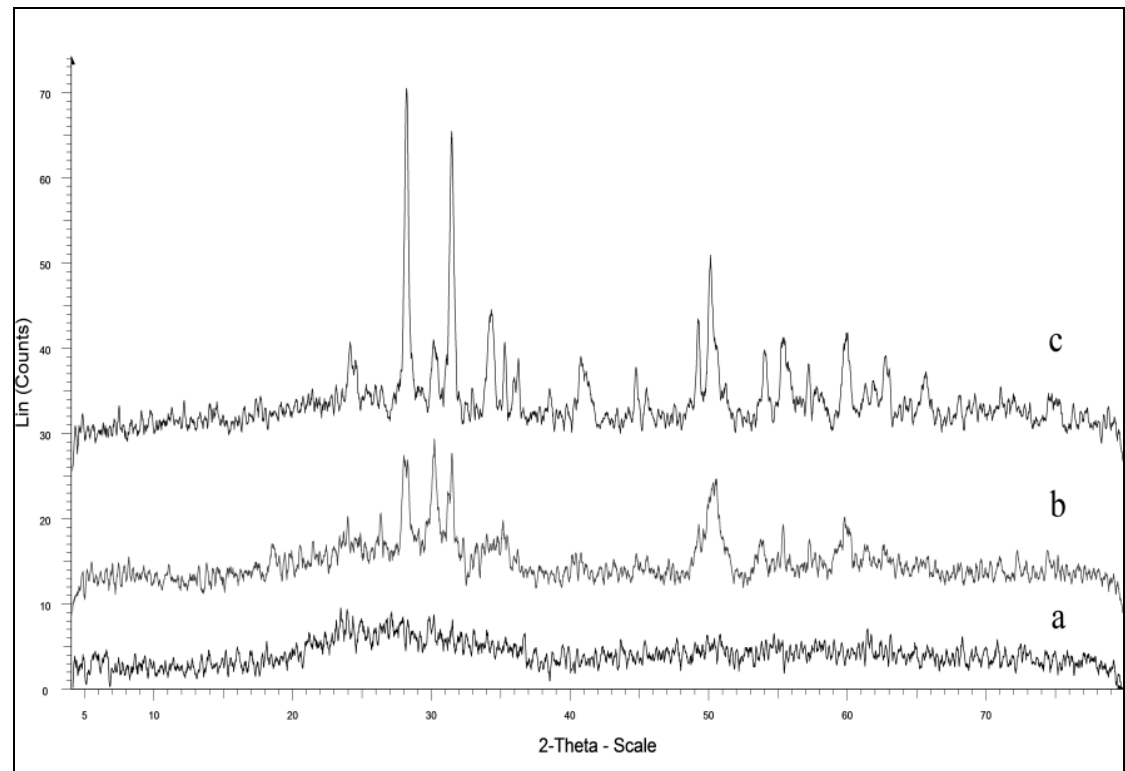

Fig. 2. XRD of $6 \% \mathrm{Zn} / \mathrm{SZ}$ calcined at (a) $500{ }^{\circ} \mathrm{C}$, (b) $600{ }^{\circ} \mathrm{C}$, and (c) $800{ }^{\circ} \mathrm{C}$.

From crystallite size calculations, it is observed that the crystallite size of undoped SZ decreases by addition of $6 \% \mathrm{Zn}$. The ionic radius of $\mathrm{Zn}^{2+}$ ion $(0.74$ $\AA)$ is smaller than $\mathrm{Zr}^{4+}$ ion $(0.84 \AA)$. Thereby replacing relatively a bigger ion $\mathrm{Zr}^{4+}$ with a smaller one $\mathrm{Zn}^{2+}$ decreases the lattice constants and changes the crystallite size. Thus, it can be concluded that the lattice disorder that happens at higher $\mathrm{Zn}$ concentration than $6 \%$ may be due to the ionic radius difference between $\mathrm{Zn}^{2+}$ and $\mathrm{Zr}^{4+}$ ions. Tewari et al. reached a similar conclusion for $\mathrm{Al}$ doped $\mathrm{ZnO}$ [55].

\section{Microscopic studies}

\section{TEM studies}

TEM images reveal the variations of particles size of $\mathrm{Zn} / \mathrm{SZ}$ with different $\mathrm{Zn}$ concentrations calcined at $500-800^{\circ} \mathrm{C}$ as shown in Fig. 3. The $6 \% \mathrm{Zn} / \mathrm{SZ}-500^{\circ} \mathrm{C}$ is amorphous, while $6 \% \mathrm{Zn} / \mathrm{SZ}-600{ }^{\circ} \mathrm{C}$ is crystalline with particle size in the range of 8.82- $16.09 \mathrm{~nm}$. By increasing calcination temperature to $800{ }^{\circ} \mathrm{C}$, very large particles $(27.9-34 \mathrm{~nm})$ with irregular and disordered shapes are observed by coming particles close to each other.

Besides the effect of calcination temperature, $\mathrm{Zn}$ concentration affects also the particle size. The particle size of SZ (7.9- $17.21 \mathrm{~nm})$ decreases by increasing $\mathrm{Zn}$ concentration up to $6 \%(8.82-16.09 \mathrm{~nm})$. In addition, a lattice distortion takes place by increasing $\mathrm{Zn}$ concentration up to $10 \%$, which in turn leads to larger particle sizes $(6.44-21 \mathrm{~nm})$.These results are in agreement with the XRD analysis.

Egypt. J. Chem. 60, No.2 (2016) 


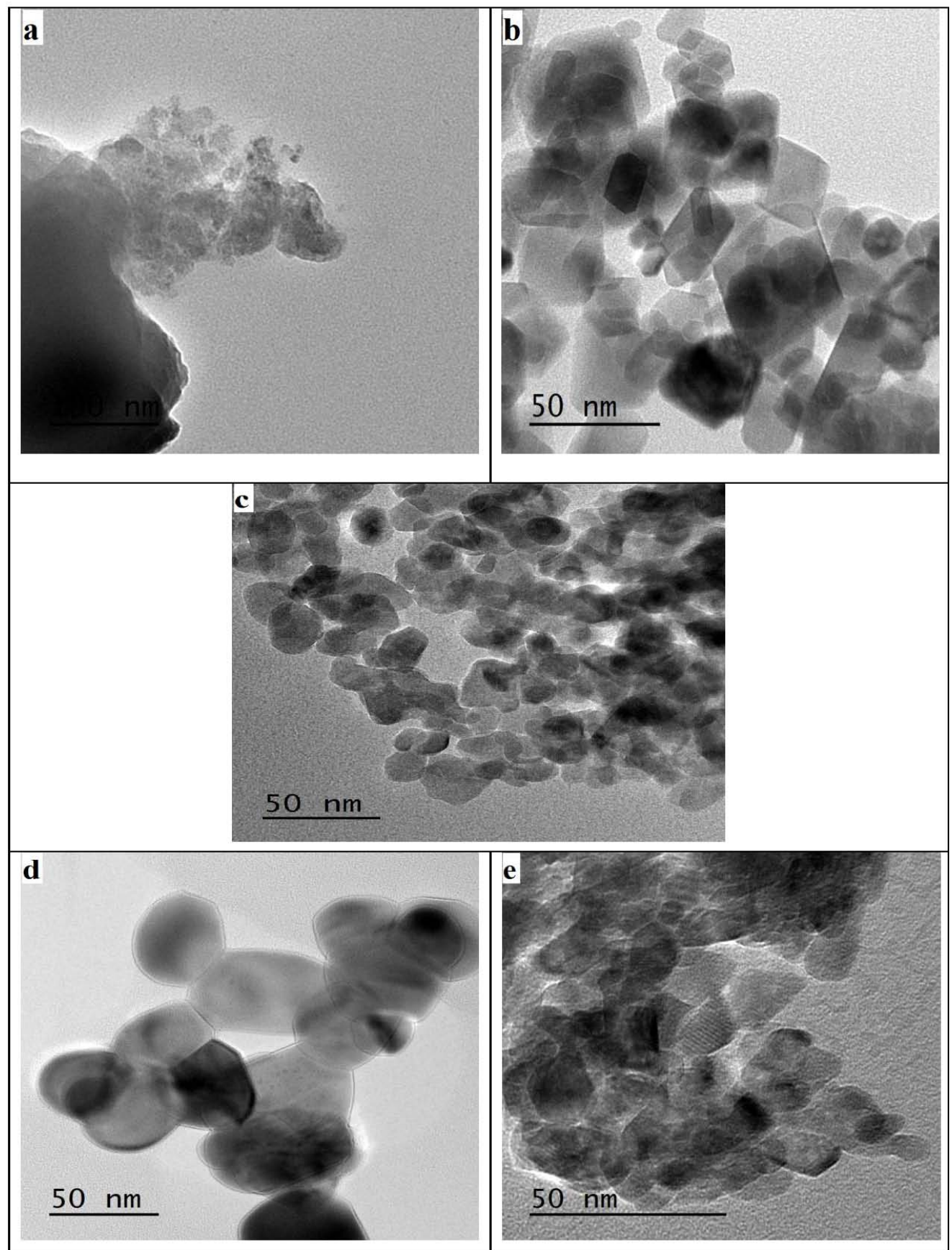

Fig. 3. TEM images of (a) $6 \% \mathrm{Zn}-\mathrm{SZ}-500{ }^{\circ} \mathrm{C}$, (b) SZ-600 ${ }^{\circ} \mathrm{C}$, (c) $6 \% \mathrm{Zn} / \mathrm{SZ}-600{ }^{\circ} \mathrm{C}$, (d) $6 \% \mathrm{Zn} / \mathrm{SZ}-800{ }^{\circ} \mathrm{C}$ and $(e) 10 \% \mathrm{Zn} / \mathrm{SZ}-600{ }^{\circ} \mathrm{C}$.

Egypt. J. Chem. 60, No.2 (2016) 
SEM studies

SEM images exhibit the surface structure of $\mathrm{SZ}$ with different $\mathrm{Zn}$ concentrations calcined at $500-800{ }^{\circ} \mathrm{C}$. As illustrated in Fig. 4 a the $6 \% \mathrm{Zn} / \mathrm{SZ}$ $500^{\circ} \mathrm{C}$ shows large particles with low homogeneity. Increasing calcination temperature up to $600{ }^{\circ} \mathrm{C}$ the particle size reduced with a better homogeneity. When calcination temperature increased to $800^{\circ} \mathrm{C}$, the particles become disordered with more agglomerations.

Figure (4b), (4c) and (4e) show SZ with different $\mathrm{Zn}$ concentrations. The $6 \% \mathrm{Zn} / \mathrm{SZ}$ catalyst reveals better homogeneity than $\mathrm{SZ}$, while $10 \% \mathrm{Zn} / \mathrm{SZ}$ shows a growth in the particles size with agglomerations. This behavior may be attributed to supersaturation effect whereas the surface coverage with particles increased by increasing $\mathrm{Zn}$ concentration leading to particles adhesion and aggregate consolidation by means of particles growth. It can be concluded that supersaturation promotes the aggregations by generating a larger particles [56].

\section{Acidity characteristics}

Potentiometric titration with n-butyl amine in acetonitrile was used to investigate the strength $\left(\mathrm{E}_{\mathrm{i}}\right)$ and the total number of acid sites for the investigated catalysts [57,58]. Table 1 and Fig. 5 indicate that increasing $\mathrm{Zn}$ concentration enhances the strength and total number of acid sites till $6 \%$ then decreased. Beside $\mathrm{Zn}$ concentration, calcination temperature exhibited a noticeable effect on the surface acidity measurements. Samples calcined at temperature from $400{ }^{\circ} \mathrm{C}$ to $600{ }^{\circ} \mathrm{C}$ show a gradual increase in the strength and the number of acid sites. This may be attributed to the increase of acidic sites by increase of dehydroxylation degree with the increase of temperature up to $600{ }^{\circ} \mathrm{C}$ [16]. By raising calcination temperature to $800{ }^{\circ} \mathrm{C}$, a sharp decrease in the strength of acid sites is observed as a result of sulfate species decomposition which leads to decrease in the ratio of Bronsted sites, hence decreasing in acidity [5,6,11].

\section{Catalytic activity}

Role of calcination temperature

It is obvious that Pechmann condensation reaction to yield coumarin is strongly dependent on calcination temperature, which affects crystalline structure, acidic and surface characteristics. As observed from Fig. 6, calcination temperature at $600{ }^{\circ} \mathrm{C}$ reveals the highest yield of coumarin. By increasing calcination temperature to $800{ }^{\circ} \mathrm{C}$ coumarin yield decreases. This may be attributed to decomposition of sulfate group producing sulfur that responsible for the active sites of sulfated zirconia by retaining on the surface. The sulfur content is inversely proportional to calcination temperature, so the activity of the catalyst decreases by increasing calcination temperature to $800{ }^{\circ} \mathrm{C}$. These results agree with XRD, TEM, SEM and acidic studies. 


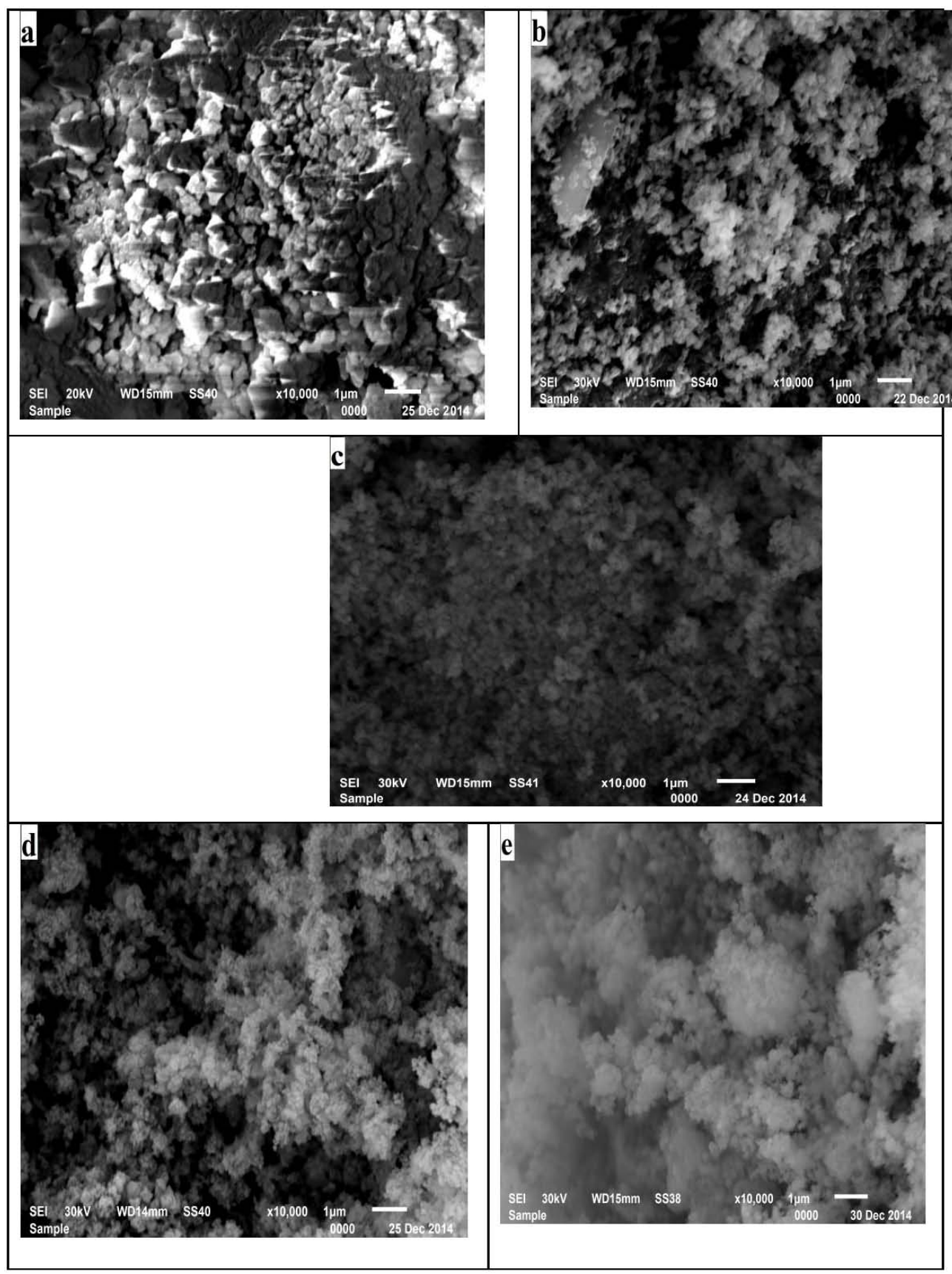

Fig. 4. SEM images (a) $6 \% \mathrm{Zn} / \mathrm{SZ}-500{ }^{\circ} \mathrm{C}$, (b) SZ-600 ${ }^{\circ} \mathrm{C}$, (c) $6 \% \mathrm{Zn} / \mathrm{SZ}-600{ }^{\circ} \mathrm{C}$, (d) $6 \% \mathrm{Zn} / \mathrm{SZ}-800{ }^{\circ} \mathrm{C}$, and (e) $10 \% \mathrm{Zn} / \mathrm{SZ}-600{ }^{\circ} \mathrm{C}$. 
TABLE 1. Acidic properties of $S Z$ and $S Z$ catalysts of different $Z n$ contents.

\begin{tabular}{|c|c|c|c|}
\hline \multirow{2}{*}{ Catalyst } & $\begin{array}{c}\text { Calcination } \\
\text { Temperature }\end{array}$ & $\mathbf{E}_{\mathbf{i}}(\mathbf{m v})$ & $\begin{array}{c}\text { Total number } \\
\text { of acid sites x 10 }\end{array}$ \\
\hline $\mathrm{SZ}$ & $600^{\circ} \mathrm{C}$ & 169.8 & 1.25 \\
\hline $4 \% \mathrm{Zn} / \mathrm{SZ}$ & $600^{\circ} \mathrm{C}$ & 320.0 & 2.52 \\
\hline \multirow{3}{*}{$6 \% \mathrm{Zn} / \mathrm{SZ}$} & $400^{\circ} \mathrm{C}$ & 304.7 & 2.35 \\
\cline { 2 - 4 } & $500^{\circ} \mathrm{C}$ & 341.4 & 2.77 \\
\cline { 2 - 4 } & $600^{\circ} \mathrm{C}$ & 382.4 & 3.01 \\
\hline $8 \% \mathrm{Zn} / \mathrm{SZ}$ & $800^{\circ} \mathrm{C}$ & 180.0 & 1.93 \\
\hline $10 \% \mathrm{Zn} / \mathrm{SZ}$ & $600^{\circ} \mathrm{C}$ & 131.4 & 1.18 \\
\hline $20 \% \mathrm{Zn} / \mathrm{SZ}$ & $600^{\circ} \mathrm{C}$ & 122.7 & 0.87 \\
\hline
\end{tabular}

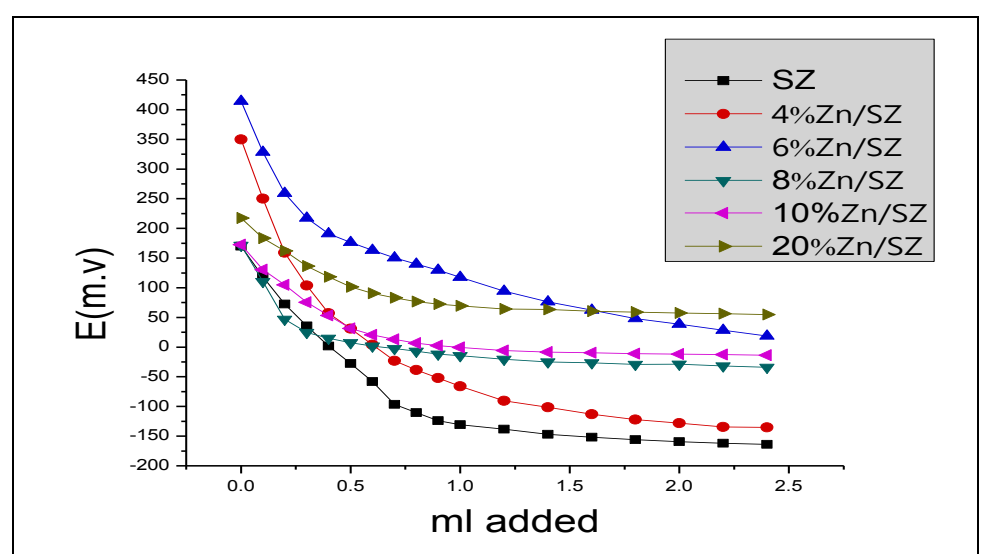

Fig. 5. Potentiometric titration curves of $\mathrm{SZ}$ with different $\mathrm{Zn}$ concentrations calcined at $600-800{ }^{\circ} \mathrm{C}$

Role of Zn concentrations on $\mathrm{SZ}$

Pechmann condensation reaction between resorcinol and ethyl acetoacetate to yield coumarin- using SZ in absence and presence of different concentrations of $\mathrm{Zn}$ is shown in Fig. 7. The $6 \% \mathrm{Zn} / \mathrm{SZ}$ catalyst exhibits the maximum coumarin yield then decreases by increasing $\mathrm{Zn}$ concentration above $6 \%$. It can be concluded that the $6 \% \mathrm{Zn} / \mathrm{SZ}$ catalyst is the most active one between the investigated catalysts. This result is confirmed by the obtained results of XRD, TEM, SEM and acidic studies. This catalyst possesses the highest content of the tetragonal phase (Fig. 1), lowest particle size $(8.82-16.09 \mathrm{~nm})$ (Fig.3c), the best homogeneity (Fig. 4c) and the maximum number of acid sites (Fig. 5 and Table $1)$. 


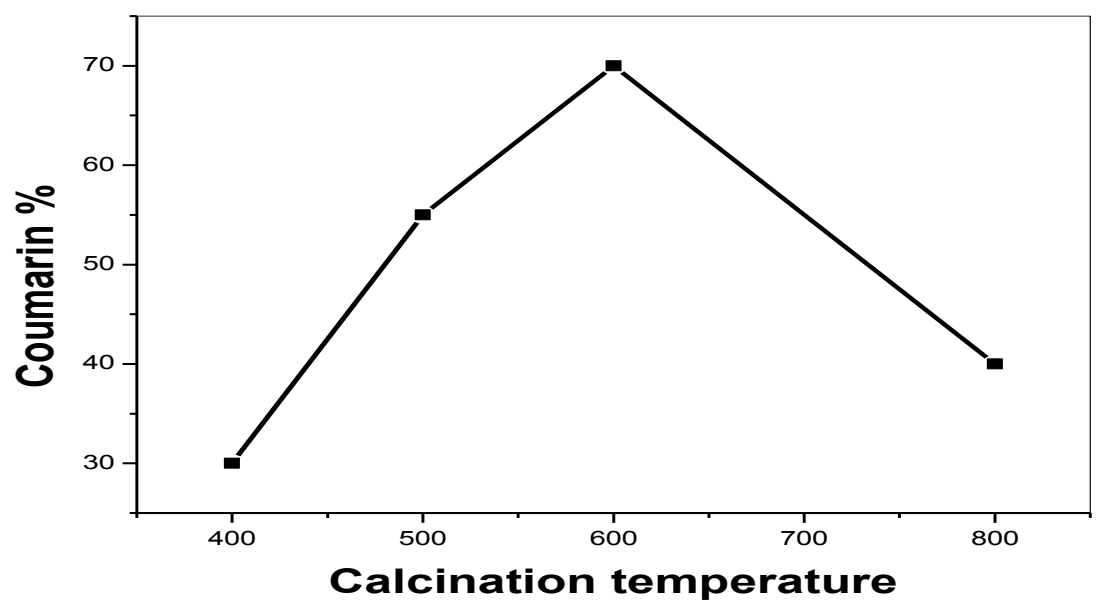

Fig.6. Effect of calcination temperature on coumarin yield.

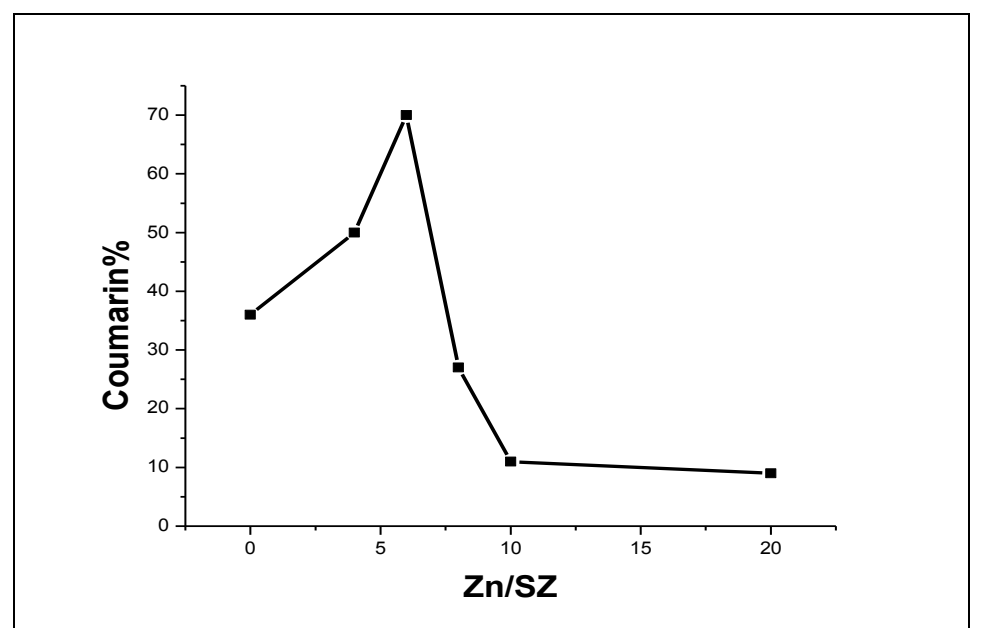

Fig. 7. Effect of $\mathrm{Zn}$ concentrations (calcination temperature is $600^{\circ} \mathrm{C}$ ) on coumarin yield.

\section{Mechanism of 7-hydroxy-4-methyl coumarin}

$\mathrm{Zn} / \mathrm{SZ}$ was used as a solid acid catalyst for Pechmann condensation of ethyl acetoacetate (EAA) and resorcinol to 7-hydroxy-4-methyl coumarin under optimum conditions based on previous results in our lab [47,48]. As reported, not only the activated group but also its position in phenol ring has an effective role on the coumarin yield due to resonance and its effect on activation of aromatic ring $[13,38]$. As well, the catalytic activity depends on the phenolic substrates activity; it is also depend on the structure of the catalyst used. The reactivity of phenol differs from one catalyst to another as follow: The yield of coumarin by 
using phenol over solid acid catalyst k-10 was $65 \%$ while over sulfated zirconia was zero [13]. Here, we obtained $70 \%$ coumarin over $6 \% \mathrm{Zn} / \mathrm{SZ}$. This may be due to the substrate is the resorcinol which is a highly activated phenol with hydroxyl group at meta position.

As reported in literature, there were two possible mechanisms for the Pechmann condensation reaction for synthesis of 7-hydroxy-4-methyl coumarin. The first one depended on proton transfer to keto group of EAA from acid sites of the catalyst by the interaction between EAA and the catalyst, and then an intermediate and ethanol are produced due to nucleophilic attack by hydroxyl group of resorcinol. The intermediate rapidly undergoes cyclization through intramolecular condensation to yield 7-hydroxy-4-methyl coumarin [39]. The second possible mechanism relied on electrophilic reaction of chemisorbed ethyl acetoacetate on resorcinol in which chromone has yielded as aside product [13, 14, 39]. In this work, the reaction followed the first mechanism illustrated in Scheme 1 . because there was no chromone obtained over any of the investigated catalysts.

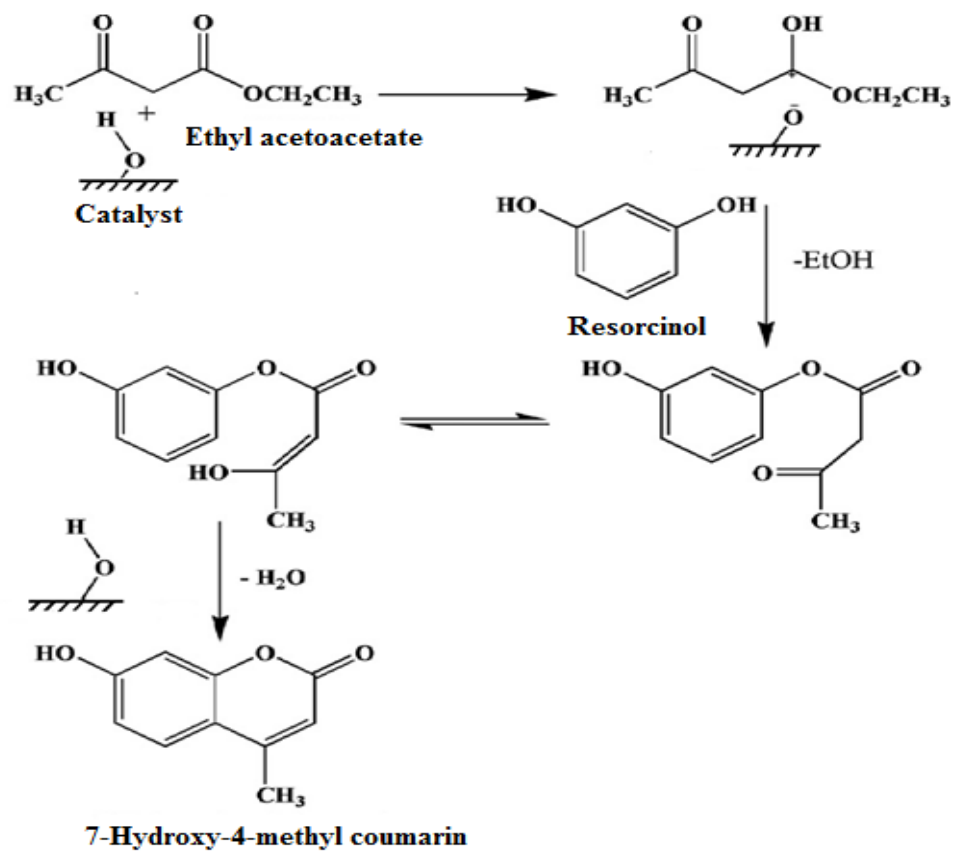

Scheme 1. Possible mechanism for the Pechmann condensation of resorcinol and EAA using Zn/SZ catalyst under solvent free condition. 


\section{Conclusion}

$\mathrm{Zn}$ doped SZ was prepared by the simple impregnation method. The $6 \% \mathrm{Zn} / \mathrm{SZ}$ catalyst calcined at $600{ }^{\circ} \mathrm{C}$ reveals the maximum yield of 7-hydroxy-4methyl coumarin under solvent free conditions. This result is correlated with $\mathrm{XRD}$, TEM, SEM and acidic studies. The $6 \% \mathrm{Zn} / \mathrm{SZ}-600^{\circ} \mathrm{C}$ possesses the maximum tetragonal phase content and the maximum number of acid sites. The coumarin did not accompanied by chromones as a side product. This confirms that the mechanism of the reaction depends on proton transfer to keto group of EAA from acid sites of the catalyst by the interaction between EAA and the catalyst.

\section{References}

1. Marakatti, V. S., Shanbhag, G. V. and Halgeri, A. B. J. Appl. Catal. A: Gen.; 451, 71-78(2013).

2. Wang, X., Wang, H., Liu, Y., Liu, F., Yu, Y. and He, H. J. Catal.; 279, 301309(2011).

3. Heshmatpour, F., Khodaiy, Z. and Aghakhanpour, R. B. J. Powd. Technol.; 224, $12-18(2012)$

4. Heshmatpour, F. and Aghakhanpour, R. B. J. Adv. Powd. Technol. 23, 8087(2012).

5. Vera, C. R., Pieck, C. L., Shimizu, K. and Parera, J. M. J. Appl. Catal. A: Gen., 230, 137-151(2002).

6. Wang, J. H. and Mou, Ch. Y. J. Catal. Today; 131, 162-172(2008).

7. Karim, A. H., Triwahyono, S., Jalil, A. A. and Hattori, H. J. Appl. Catal. A: Gen.; 433-434, 49-57(2012)

8. Mugniery, X.Chafik,T., Primet,M. and Bianchi,D. J. Catal. Today; 52, 1522(1999).

9. Boffito, D.C., Crocellà, V., Pirola,C., Neppolian, B., Cerrato, G., Ashokkumar, M. and Bianchi, C. L. J. Catal.; 297, (2013) 17-26.

10. López, D.E., Suwannakarn, K. Bruce, D. A. and Goodwin Jr, J. G. J. Catal.; 247, 43-50(2007).

11. Gao, S., Chen, X., Wang, H., Mo, J., Wu, Z., Liu, Y. and Weng, X., J. Coll. and Interf. Sci.; 394, 515-521(2013).

12. Pietrogiacomi, D., Magliano, A., Ciambelli, P., Sannino, D., Campa, M. C. and Indovina, V. J. Appl. Catal. B. Environ.; 89, 33-40(2009).

13. Sinhamahapatra, A., Sutradhar, N., Pahari, S., Bajaj, H. C. and Panda, A. B. J. Appl. Catal. A: Gen.; 394, 93-100(2011). 
14. Ghodke, S. and Chudasama, U. J. Appl. Catal. A: Gen.; 453, 219- 226(2013).

15. Tyagi, B., Mishra, M. K. and Jasra, R. V. J. Mol. Catal. A: Chem.; 276, 4756(2007).

16. Osiglio, L., Sathicq, A. G., Romanelli, G. P. and Blanco, M. N. J. Mol. Catal. A: Chem., 359, 97-103(2012).

17. Fraenkel, D., Jentzsch, N. R., Starr, Ch. A. and Nikrad, P. V. J. Catal.; 274, 2951(2010).

18. Essayem, N., Martin, V., Riondel, A. and. Ve'drine, J. C. J. Appl. Catal. A:Gen.; 326, 74-81(2007).

19. Deshmane, V. G. and Adewuyi, Y. G. J. Appl. Catal. A: Gen.; 462- 463, 196 206(2013).

20. Wang, J. H. and Mou, Ch. Y. J. Appl. Catal. A: Gen.; 286, 128-136(2005).

21. Yadav, G. D. , Ajgaonkar, N. P. and Varma, A. J. Catal.; 292, 99-110(2012).

22. Lacy, A. and OKennedy, R. J. Current Pharm. Design; 10 (2004) 3797-3811.

23. Recillas, A. S., Vázquez, G. N., Figueroa, S. H., Rios, M. Y., Barajas, M. I. and. Soto, S. E. Eur. J. Med. Chem. 77 (2014) 400-408.

24. Huang, M., Xie, S.S., Jiang, N., Lan, J. Sh. Kong, L. Yi and Wang, X. B. J. Bioorg. Med. Chem., 25, 508-513(2015).

25. Liu, J., Wua, F., Chen, L., Zhao, L., Zhao, Z., Wang, M. and Lei, S. J. Food Chem., 135, 2872-2878(2012).

26. Ma, J. Sheng, R., Wu, J., Liu, W. and Zhang, H., Sens, J. and Actuat. B; 197 364-369(2014)

27. Keskina, S. S., Aslan, N. and Bayrakceken, F. J. Spectrochim. Acta Part A; 72, 254-259(2009).

28. Bakhtiari, G., Moradi, S. and Soltanali, S. Arab. J. Chem., 7, 972-975(2014) .

29. Abd El-Wahab, H., Abd El-Fattah, M., Abd El-Khalik, N., Nassar, H. S. and Abdelall, M. M. G., J. Prog. Org. Coat., 77, 1506-1511(2014).

30. Pingaew, R., Saekee, A., Mandi, P., Nantasenamat, C., Prachayasittikul, S., Ruchirawat, S. and Prachayasittikul, V. Eur. J. Med. Chem., 85, 65-76(2014).

31. Rajabi, M., Hossaini, Z., Khalilzadeh, M. A., Datta, Sh., Halder, M. and Mousa, Sh. A. J. Photochem. Photobiol. B: Biol.; 148, 66-72(2015).

32. Zhang, W., Li, Z., Zhou, M., Wu, F., Hou, X., Luo, H., Liu, H., Han, X., Yan, G., Ding, Z. and Li, R. J. Bioorg. Med. Chem. Lett., 24, 799-807(2014).

Egypt. J. Chem. 60, No.2 (2016) 
33. K. Matsuda, Sh. Hattori, R. Kariya, Y. Komizu, E. Kudo, H. Goto, M. Taura, R. Ueoka, Sh. Kimura, and S. Okada; J. Biochem. Biophys. Res. Comm., 457, 288294(2015).

34. Witaicenis, A., Seito, L. N., Chagas, A. D. S., L. D. d- A. Junior, A. C. Luchini, Orsi, P. R., Cestari, S. H. and Stasi, L. C. D. J. Phytomed., 21, 240-246(2014) .

35. Hwu, J. R., Kapoor, M. , Tsay, S. C., Lin, C. C., Hwang, K. C., Horng, J.C., Chen, I.C., Shieh, F. K., Leyssen, P. and Neyt, J. J. Antivir. Res.; 118, 103109(2015).

36. Kalita, P. and Kumar, R. J. Microp. and Mesop. Mater.; 149 1-9(2012).

37. Zareyee, D. and Serehneh, M. J. Mol. Cata. A: Chem.; 39,188-91(2014) .

38. Karami, B. and Kiani, M. J. Catal. Comm., 14, 62-67(2011).

39. Heravi, M. M., Khaghaninejad, S. and Mostofi, M. J. Adv. Hetero.Chem. 112 150(2014)

40. Devassy, B. M., Lefebvre, F., Bohringes, W., Fletcher, J. and Halligudi, S. B. $J$. Mol. Catal A: Chem.; 236, 162-167(2005).

41. Patterson, A. J. Phys. Rev., 56, 978-982(1939).

42. Jenkins, R. and Snyder, R. L. J. Chem. Anal., 138, 335-339(1996).

43. Vos, K., Vandenberghe, N. and Elsen,J. J. Earth Sci. Rev.; 128, 93-104(2014).

44. K. N. Rao, K. M. Reddy, N. Lingaiah, I. Suryanarayana, and. Prasad, P. S. S J. Appl. Catal. A: Gen.; 300, 139-146(2006).

45. Sethna, S. and Phadke, S. M. J. Org. Reac.; 7, 1-58(1953).

46. Shockravi, A. and Valizadeh, H., J. Tetrahed. lett.; 46, 3501-3503(2005)

47. Ahmed, A. I., El-Hakam, S. A., Khder, A. S. and Abo El-Yazeed, W. S., J. Mol. Catal. A: Chem.; 366 99-108(2013).

48. EL-Hakam, S. A., Hassan, Sh. M., Ahmed, A. I. and ELDafrawy; Sh. M. J. Ameri. Sci., 7 682-693(2011).

49. Tyagi, B., Mishra, M. K. and Jasra, R.V. J. Mol. Catal. A: Chem., 276, 47-56 (2007).

50. Sang, X., Zhang, L., Wang, H., He , D., Deng, L., Huang, S., Wang, J. and Luo, Y. J. Powd. Technol.; 253, 590-595(2014).

51. Rekha, M., Manjunath, H.R. and Nagaraju, N. J. Ind. Eng. Chem.; 19, 337346(2013). 
52. Kato, K., T. Saito, Sh. Shibayama, M. Sakashita, W. Takeuchi, N. Taoka, O. Nakatsuka, and Sh. Zaima; J. Thin Sol. Films; 557, 192-196(2014).

53. Kumar, S., Bhunia, S. and Ojha, A. K. J. Phys. E; 66, 74-80(2015).

54. Rui , R., Duan, W., Xiaodong, W. Jun, F. Lei, W. and Xiaodi , W. J. Rare Earths; 29, 1053-1059(2011)

55. Tewari, S. and Bhattacharjee, A. J. phys.; 76, 153-163(2011)

56. J. M. Kim, S. - M. Chang, J. H. Chang, and W.S. Kim; J. Coll. and Surf. A: Physicochem. Eng. Aspects; 384, 31-39(2011)

57. Reddy K. M., Lingaiah N., Prasad,P. S. S. and Suryanarayana; I., J. Sol. Chem.; 35, 407-423(2006)

58. Alaya,M.N. and Rabah, M.A. J. Alloys and Comp.; 575, 285-291(2013).

(Received 15/11/2016 ;

Accepted 22/12/2016 ) 
الخواص التركيبيه والحفزيه لحفازات الزيركونيا المسلفنه المطعمه باكسيد الزنك

شادي محمد الدفراوي ، مرفت فراج ، سهير عبد الحكم و شوقي محمد حسن

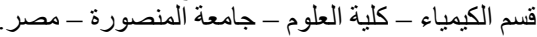

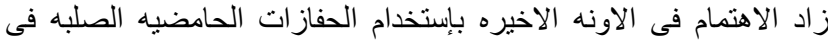

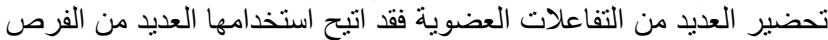

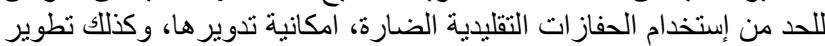

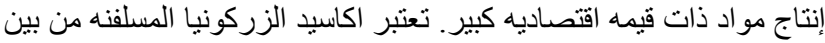

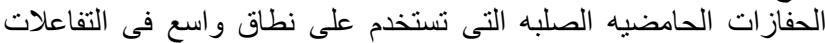

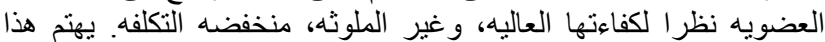

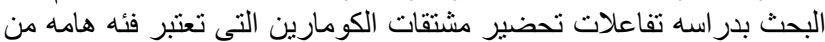

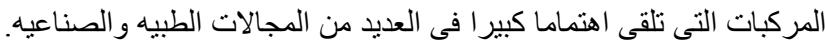

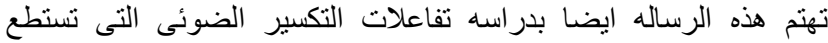

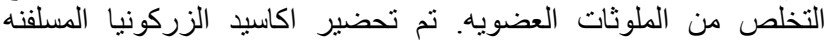

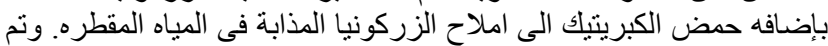

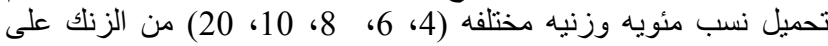

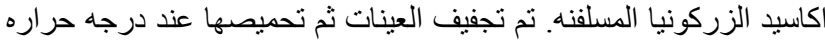

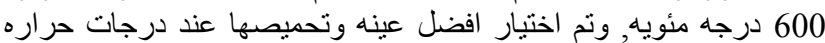

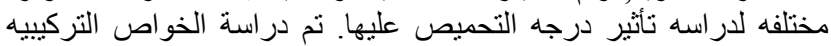

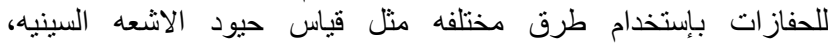

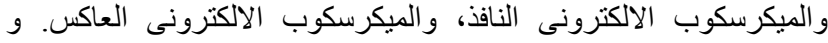

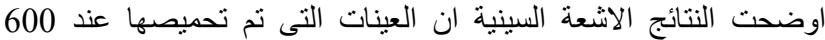

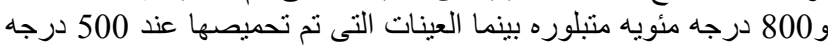

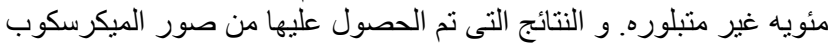

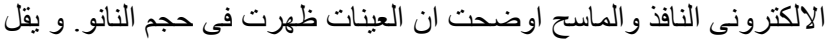

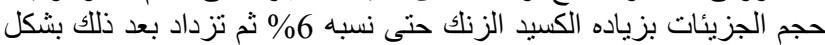

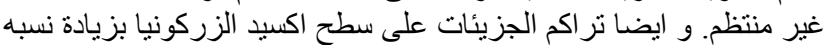

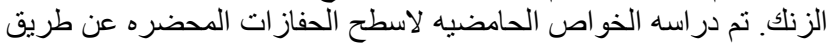

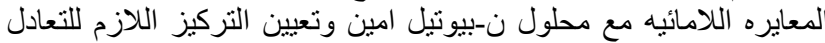

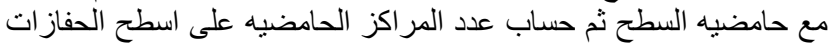

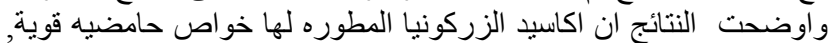

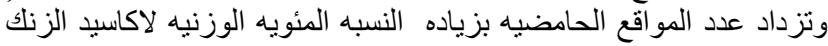

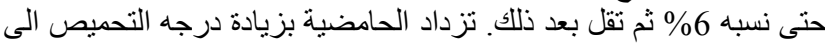

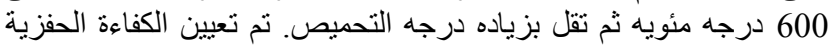

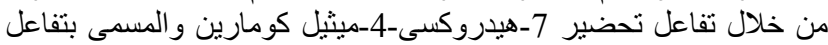

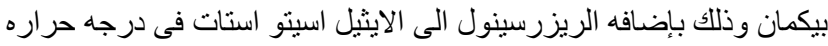

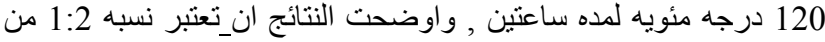

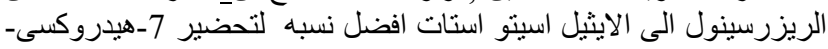

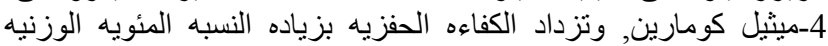

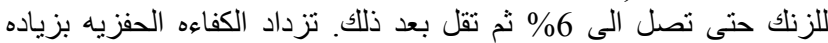
درجه التحميص حتى 600 درجه مئويه ثم تقل بعد ذلك. 